\title{
Characteristics of a Mycobacterium Strain (Chabotier) Isolated from a Leprosy Patient
}

\author{
SOEUR MARIE DE LA TRINITE \\ Director, Laboratoire de Recherches sur la Lèpre, ${ }_{2} 5$ Rue du Plat, Lyon, Rhone, France
}

In I 939, at the Hospital St Louis, Paris, a skin biopsy was taken for examinations from a nonulcerated ear-lobe lesion of a patient suffering from advanced lepromatous leprosy. Part of the biopsy material was put into sterile distilled water in a sterile tube which was then sealed and kept at room temperature. This material was later examined by Sister Marie-Suzanne and the author, and the bacteriological findings are described in the following report. In I 954 it was found that the tissue sample in water had disintegrated and smears from it and the supernatant liquid showed acid-fast bacilli and numerous homogenous cyanophil 'coccal' bodies. Cultures were made on Lowenstein-Jensen medium and on glycerol agar. After eight weeks at $37 a ́$ C., a culture of a rough light-yellow Mycobacterium strain had developed on Lowenstein-Jensen medium. Smears showed the organism to consist of long acid-fast bacilli intermixed with non-acid fast cyanophil 'coccal' bodies. On glycerol agar, a whitish confluent growth was produced which included some wrinkled chromogenic areas. Smears from this growth showed shorter and more granular acid-fast bacilli and again these were mixed with 'coccal' elements.

The biopsy tissue in water was re-examined periodically up until the end of r955 during which time a decrease in the numbers of cyanophil cocci was noted but there was an increase of fuchsinophil refringent granules a gradual increase in numbers of pleomorphic acid-fast bacilli was noted. In February i 956, a pure culture of the Mycobacterium strain was obtained on solid medium, the cyanophil elements no longer being apparent. The strain grew very sparsely in a liquid medium at first, but cultures in Sauton medium were later grown from the tissue in the form of a wrinkled lightyellow surface pellicle. Once again cyanophil cocci were interspersed with the acid-fast bacilli in this growth.

Subcultures from the Mycobacterium strain (named 'Chabotier') grew progressively more readily in serial transfers and a brief summary of their properties is given below.

Properties of the Mycobacterium strain ('Chabotier') subcultures

Bacillary morphology - Acid-fast cocco-bacilli Colony morphology on Lowenstein-Jensen medium - Smooth glistening yellow colonies develop; pigment develops in dark as well as light.

Growth rate:

(a) Lowenstein-Jensen medium - Colonies begin to appear in 5 days at $37^{\circ} \mathrm{C}$. and rather later at $26^{\circ} \mathrm{C}$.

(b) Nutrient agar - Growth develops more slowly than in (a).

For comparison with other mycobacteria see Table I - Biochemical reactions (see Table II) :

(a) Niacin production - Negative.

(b) Catalase test - Positive.

(c) Peroxidase test - Negative.

(d) Arylsulphatase test - Negative.

(e) Amidase tests (carried out by Dr E. Nassau, Harefield Hospital, Middlesex, England).

Only urea was split amongst the following substances tested: acetamide, benzamide, nicotinamide, succinamide, propionamide, valermide, pyrazinamide, urea.

Animal inoculation studies:

(a) Guinea pig inoculated intracardially with I mgm., of the moist culture showed no pathological changes when examined I 2 weeks later Mantoux test using I ooo T.U. Weybridge PPD was negative 5 weeks after inoculation. (Carried out by Dr E. Nassau, Harefield Hospital, Middlesex, England). 
(b) Mouse foot pad and muscle inoculation. The tests have been carried out by E. Palmer, R. J. W. Rees, G. Weddell (National Institute for Medical Research, London and Department of Human Anatomy, Oxford) and the results will be included in a separate paper by them.

\section{CONGLUSION}

The Mycobacterium strain ('Chabotier') may be described as urease-positive Scotochromogen (Runyon Group II). It is distinct from Myco. marianum.

TABLE I

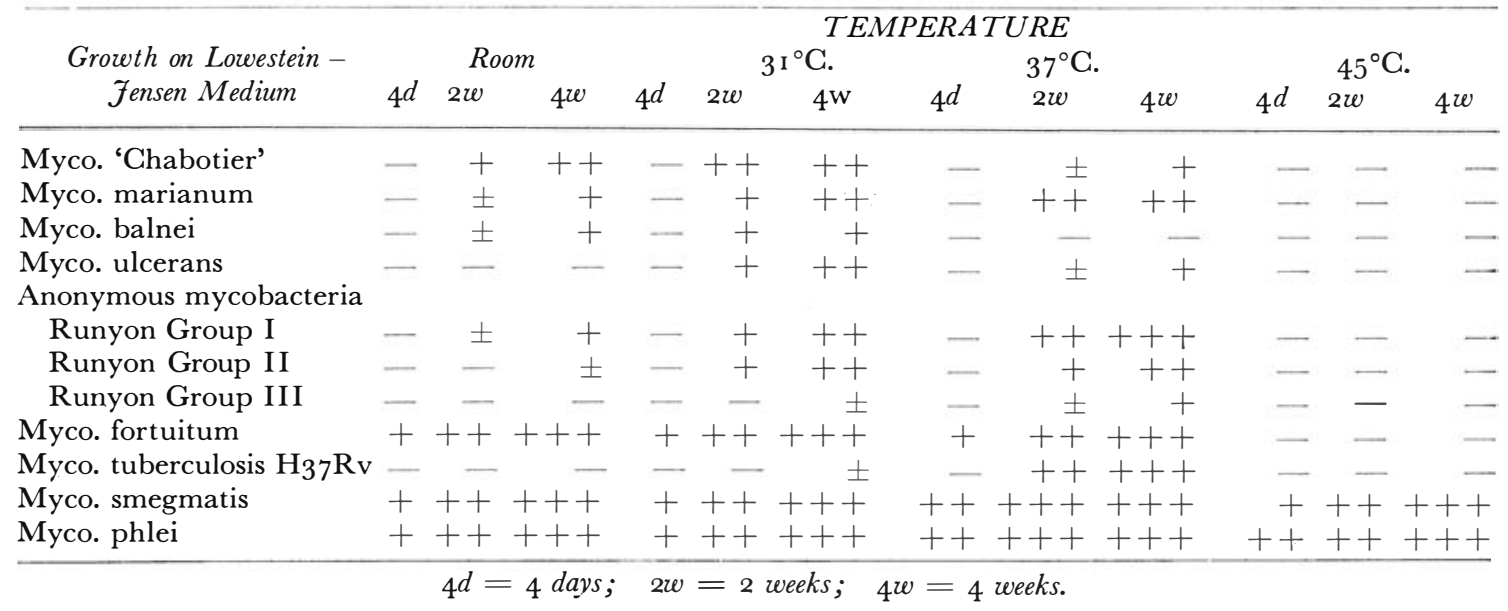

TABLE II

\begin{tabular}{|c|c|c|c|c|}
\hline & $\begin{array}{c}\text { Niacin } \\
\text { production }\end{array}$ & $\begin{array}{c}\text { Catalase } \\
\text { activity }\end{array}$ & $\begin{array}{c}\text { Peroxidase } \\
\text { test }\end{array}$ & $\begin{array}{c}\text { Aryl- } \\
\text { sulphatase test }\end{array}$ \\
\hline Мyco. 'Chabotier' & o & + & o & o \\
\hline Myco. marianum & o & ++ & o & o \\
\hline Myco. balnei & o & + & o & + \\
\hline Myco. ulcerans & o & + & + & o \\
\hline \multicolumn{5}{|l|}{ Anonymous mycobacteria } \\
\hline Runyon Group I & o & + & o & + \\
\hline Runyon Group II & o & + & o & o \\
\hline Runyon Group III & o & + & ++ & + \\
\hline Myco. fortuitum & o & +++ & o & ++ \\
\hline Myco. tuberculoiss $\mathrm{H}_{37} \mathrm{Rv}$ & + & + & ++ & o \\
\hline Myco. smegmatis & o & + & o & o \\
\hline Myco. phlei & o & + & o & o \\
\hline
\end{tabular}

\section{DISCUSSION}

The isolation of Anonymous mycobacteria and Saprophytic mycobacteria strains from the lesions of patients suffering from leprosy has been recorded from time to time, particularly from ulcerated areas. The purpose of the present report is to stress the need for detailed studies on such strains since, at the moment, they are often not adequately investigated in the fields of leprosy and dermatology. In the study of patients with respiratory diseases much work has been done on the various mycobacteria but even here the role of Anonymous mycobacteria is still not fully elucidated. Furthermore, there is insufficient information on their incidence in different parts of the world, particularly in tropical areas. 
The incidence of Anonymous mycobacteria varies with individual investigations. In Britain, of 3,000 strains of mycobacteria studied in the Public Health Laboratory Service ( I 962), almost all from sputa of 'new' patients, I.4\% were considered to be 'clinically significant' Anonymous organisms and a further I.I \% were 'non-significant'. In a Lagos study by Beer and Davis, (I965) $6 \%$ of cultures of mycobacteria isolated in the course of routine examination of sputa were anonymous in type, mostly Runyon Groups III and IV. Recordings such as these are probably a gross under-estimate of the true incidence of these strains. It is probably true to say that in skin diseases the division between what are clinically significant Anonymous mycobacteria and what are merely commensal organisms or saprophytes has received only very limited study.

Whereas the photochromogenic Runyon Group I strains (Myco. kansasii) are probably the most significant pulmonary pathogens, Group III (Battey type) organisms are also well-known as causes of tuberculosis-like disease. The scotochromogens (Group II) and Rapid Growers (Group IV) are considered to be usually commensals or saprophytes, but the former is well known as a cause of scrofula-like cervical lymphadenitis particularly in debilitated subjects. Not included amongst the Runyon Group strains are the skin pathogens Myco. balnei (Linell and Norden, I954) which is scotochromogenic and Myco. ulcerans (MacCallum et al, r 948) which is not pigmented. Mycobacterium marianum (Marie-Suzanne et al, I 952) appears to be an Anonymous mycobacterium and this was isolated from a non-ulcerated lesion of a leprosy patient. The heterogeneity of many of these 'strains' is exemplified by the recent work of Navalkar et al, ( I 964) who showed that Myco. marianum strains may differ in their mycoside content.

In this study of the scotochromogen 'Chabotier' it is impossible to conclude whether the organism was a contaminant which gained entry at the time of biopsy or later during subculturing, or whether it was present in the ear-lobe lesion of the leprosy patient concerned. It is a fact that the amidase test results reported above suggest it is a 'human' strain, but it is also known that some scotochromogens split urea whereas others do not. The value of amidase tests in this respect is still a matter of controversy.

The 'coccal' elements and 'granules' seen at different stages of culture of the 'Chabotier' chromogen may possibly have been of similar nature to those described by Csillag (ig63). These develop in rapidly-growing organisms which are not acid-fast during stages in the culture of Myco. tuberculosis and Anonymous mycobacteria. They resemble the endospores of Bacillaceae. Czillag reported that a Myco. tuberculosis $\mathrm{H}_{37} \mathrm{Rv}$ strain which had been maintained for many years on Lowenstein-Jensen medium yielded sporulating forms only after 27 weeks incubation. This aspect of the 'Chabotier' organism was not pursued in this study.

Browne (1964) has emphasised the practical bacteriological difficulties in the investigation of leprosy patients, and has stressed the high value of recently developed laboratory investigations in the Genus Mycobacterium.

\section{S U M M A R Y}

A Mycobacterium strain ('Chabotier') isolated from the biopsy specimen of a non-ulcerated ear-lobe lesion of a patient who suffered from lepromatous leprosy is described and compared with other Mycobacterium strains. It is concluded that the organism is a urease positive scotochromogen of Runyon Group II. It is distinct from Myco. marianum.

\section{A CKNOWLEDGEMENTS}

Dr R. G. Cochrane, Leprosy Research Fund, London is acknowledged for help in initiating the various aspects of the study. The advice of $\mathrm{Dr}$ R. W. Riddell, Brompton Hospital, London is also acknowledged.

\section{REFERENCES}

BeER, A. G., and Davis, G. H. G., Tubercle, Lond., 46, 32, I 965 .

BROWNE, s. G., Ibid., 45, 56, I 964 .

CSILlaG, A., Ibid., 44, 368. I 963 .

linell, f., and norden, A., Acta Tuberc. Scand., Supp. 33. I 954 .

macCAllum, P., TOlhurst, J. C., BUCKLE, G., and sissons, H. A., 7. Path. Bact., 6o, 93, 1948.

marie-suzanne, soeur, noel, R., and sohier, r., Ann. Inst., Pasteur, 82, 50, I $95^{2}$.

NAVAlkar, R. G., Wiegeshaus, E. H., and smith, D. w., 7 . Bact., 88, 255, I 964 .

Public Health Laboratory Service, Tubercle, Lond., 43, 432, I 962 . 